\title{
Systematic review of performance-enhancing health worker supervision approaches in low- and middle-income countries
}

\author{
Rachel Deussom ${ }^{1 *} \mathbb{D}$, Doris Mwarey², Mekdelawit Bayu', Sarah S. Abdullah and Rachel Marcus ${ }^{3}$
}

\begin{abstract}
Background: The strength of a health system - and ultimately the health of a population — depends to a large degree on health worker performance. However, insufficient support to build, manage and optimize human resources for health $(\mathrm{HRH})$ in low- and middle-income countries (LMICs) results in inadequate health workforce performance, perpetuating health inequities and low-quality health services.

Methods: The USAID-funded Human Resources for Health in 2030 Program (HRH2030) conducted a systematic review of studies documenting supervision enhancements and approaches that improved health worker performance to highlight components associated with these interventions' effectiveness. Structured by a conceptual framework to classify the inputs, processes, and results, the review assessed 57 supervision studies since 2010 in approximately 29 LMICS.
\end{abstract}

Results: Of the successful supervision approaches described in the 57 studies reviewed, 44 were externally funded pilots, which is a limitation. Thirty focused on community health worker (CHW) programs. Health worker supervision was informed by health system data for 38 approaches (67\%) and 22 approaches used continuous quality improvement (QI) (39\%). Many successful approaches integrated digital supervision technologies (e.g., SmartPhones, mHealth applications) to support existing data systems and complement other health system activities. Few studies were adapted, scaled, or sustained, limiting reports of cost-effectiveness or impact.

Conclusion: Building on results from the review, to increase health worker supervision effectiveness we recommend to: integrate evidence-based, QI tools and processes; integrate digital supervision data into supervision processes; increase use of health system information and performance data when planning supervision visits to prioritize lowestperforming areas; scale and replicate successful models across service delivery areas and geographies; expand and institutionalize supervision to reach, prepare, protect, and support frontline health workers, especially during health emergencies; transition and sustain supervision efforts with domestic human and financial resources, including communities, for holistic workforce support. In conclusion, effective health worker supervision is informed by health system data, uses continuous quality improvement (QI), and employs digital technologies integrated into other health system activities and existing data systems to enable a whole system approach. Effective supervision enhancements

\footnotetext{
*Correspondence: rdeussom@hrh2030program.org

${ }^{1} \mathrm{HRH} 2030$ Program, Chemonics International, 1717 H Street NW, Washington, DC 20006, United States of America

Full list of author information is available at the end of the article
}

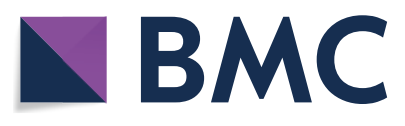

(c) The Author(s) 2021. Open Access This article is licensed under a Creative Commons Attribution 4.0 International License, which permits use, sharing, adaptation, distribution and reproduction in any medium or format, as long as you give appropriate credit to the original author(s) and the source, provide a link to the Creative Commons licence, and indicate if changes were made. The images or other third party material in this article are included in the article's Creative Commons licence, unless indicated otherwise in a credit line to the material. If material is not included in the article's Creative Commons licence and your intended use is not permitted by statutory regulation or exceeds the permitted use, you will need to obtain permission directly from the copyright holder. To view a copy of this licence, visit http://creativecommons.org/licenses/by/4.0/. The Creative Commons Public Domain Dedication waiver (http://creativeco mmons.org/publicdomain/zero/1.0/) applies to the data made available in this article, unless otherwise stated in a credit line to the data. 
and innovations should be better integrated, scaled, and sustained within existing systems to improve access to quality health care.

Keywords: Human resources for health, Health workforce, Workforce development, Supportive supervision, Health systems, Performance management, Enhanced supervision, Systematic review, Quality improvement

\section{Background}

Health systems largely depend on health worker performance to provide health for all $[1,2]$. However, insufficient support to build, manage and optimize human resources for health $(\mathrm{HRH})$ results in an insufficient quantity of health care workers (HCWs) in low- and middle-income countries (LMICs), which in turn perpetuates health inequities and produces low-quality health services $[3,4]$.

$\mathrm{HCW}$ supervision is intended to improve the quality and coverage of health services. However, its effectiveness is dependent on the context, availability of other health systems inputs, implementation factors, and the means of and level at which supervision is evaluated[5]. Bailey et al.s [6] systematic review of health worker supervision concluded it "[did] not find a solid foundation on which to base clear conclusions on the effect of supportive supervision on quality of care or clinical outcomes; supportive supervision alone, however, does not seem to be effective in improving quality of care in contexts, where the required health system inputs are inadequate." Supervision program parameters are often ill defined, and there is limited evidence on the direct attribution of supervision beyond HRH performance, motivation and satisfaction, to broader clinical and health outcomes.

Per Rowe et al. [5] components of supervision programs vary greatly depending on the country and scale of implementation, health focus area, funding source, and availability of other health systems inputs. The large HCPPR database reviewed five decades of literature to assess the HCW supervision and its effectiveness-whether positive or negative-when combined with a range of other performance interventions. However, for country governments and practitioners seeking evidence and best practices on how to implement effective HCW supervision, there is limited elaboration and discussion of the practical inputs and processes of effective supervision systems, particularly as emerging health threats further constrain health systems and HCW support is needed more than ever. In addition, as many countries seek to expand the reach of primary health care services through community health programming, there is heightened need to ensure that all health workers are adequately supported and supervised to deliver high-quality care.
Our systematic review sought to identify and analyze the components of recently implemented interventions designed to strengthen $\mathrm{HCW}$ supervision in LMICs that demonstrated improved health workforce performance or other positive health system effects. We then conducted a structured analysis of the identified interventions to describe the inputs and processes underpinning each successful supervision approach.

\section{Methods}

The USAID-funded Human Resources for Health in 2030 (HRH2030) Program undertook a database search of white and grey literature to gather evidence on supervision approaches using defined terms and inclusion criteria. The first-round search was conducted in June 2018 and updated in October 2020. Our information sources included randomized controlled trials, quasi-experimental studies, scoping reviews, end-of-project reports, systematic reviews, qualitative studies, journal articles, country case study reports, technical briefs, and conference presentations, among others (Table 1).

For analysis, we adapted the conceptual framework developed by Dieleman et al. [7] to build on previously defined dimensions of $\mathrm{HCW}$ performance, adding in performance indicators used by the World Health Organization's Global Health Workforce Alliance [8] (Fig. 1).

Articles meeting our review criteria were examined to ensure their relevance to health worker supervision and were assessed for the quality of their methodology using Critical Appraisal Skills Program (CASP) checklists for the studies relevant to the available checklists. A team of four reviewers identified, classified, and analyzed a total of 57 articles using an Excel-based template of the framework, noting emerging themes and patterns across different settings, health worker types, program goals, modalities, pedagogies, other enhancements, and complementary interventions. We analyzed each intervention to qualify and summarize the inputs, processes, and results of the supervision approach and then classified them using the framework categories. Framework categories to classify approaches were modified as new themes emerged during analysis. We then conducted a quantitative analysis to determine the frequencies for each category. Finally, to develop our main recommendations for enhancing supervision, we conducted a qualitative analysis to extrapolate the most 
Table 1 Enhanced supervision search results disaggregated by database

\begin{tabular}{|c|c|c|c|c|c|c|c|}
\hline Database & $\begin{array}{l}\text { Initial search } \\
\text { results }\end{array}$ & $\begin{array}{l}\text { After removing } \\
\text { repeats }\end{array}$ & $\begin{array}{l}\text { Related } \\
\text { to health } \\
\text { (for multi- } \\
\text { disciplinary } \\
\text { databases) }\end{array}$ & Since 2010 & In English & $\begin{array}{l}\text { Further search } \\
\text { using database } \\
\text { filters }\end{array}$ & $\begin{array}{l}\text { Relevance of title } \\
\text { \& abstract }\end{array}$ \\
\hline $\begin{array}{l}\text { Cochrane Data- } \\
\text { base of system- } \\
\text { atic reviews }\end{array}$ & 313 & 309 & 281 & 226 & 226 & 226 & 3 \\
\hline $\begin{array}{l}\text { Global Health: } \\
\text { Science \& Prac- } \\
\text { tice journal }\end{array}$ & 312 & 144 & 33 & 27 & 27 & 27 & 32 \\
\hline $\begin{array}{l}\text { GlobalHealth \& } \\
\text { PubMed }\end{array}$ & 222 & 222 & 170 & 103 & 103 & 103 & 33 \\
\hline $\begin{array}{l}\text { Health Care } \\
\text { Provider Perfor- } \\
\text { mance Review } \\
(\text { HCPPR) }\end{array}$ & 118 & 118 & 12 & 3 & 3 & 3 & 3 \\
\hline $\begin{array}{l}\text { Health Systems } \\
\text { Evidence }\end{array}$ & 543 & 531 & 156 & 287 & 287 & 287 & 1 \\
\hline $\begin{array}{l}\text { Healthcare } \\
\text { Management } \\
\text { Information } \\
\text { Consortium } \\
\text { (HMIC) }^{\text {a }}\end{array}$ & 0 & 0 & 0 & 0 & 0 & 0 & 0 \\
\hline $\begin{array}{l}\text { HRH Global } \\
\text { Resource } \\
\text { Centre }^{\mathrm{a}}\end{array}$ & 94 & 94 & 15 & 79 & 79 & 79 & 6 \\
\hline $\begin{array}{l}\text { mHealth } \\
\text { Compendium }^{\text {Databases }}{ }^{\mathrm{a}}\end{array}$ & 80 & 16 & 16 & 16 & 16 & 16 & 4 \\
\hline Popline & 49,873 & 49,873 & 118 & 118 & 118 & 118 & 3 \\
\hline $\begin{array}{l}\text { References from } \\
\text { Bailey et al. [6] }\end{array}$ & 10 & 10 & 10 & 10 & 10 & 10 & 10 \\
\hline ResearchGate & 133 & 132 & 132 & 110 & 108 & 108 & 8 \\
\hline The Lancet & 40 & 36 & 13 & 9 & 9 & 9 & 4 \\
\hline USAID DEC & 15,488 & 15,439 & 4052 & 2972 & 2972 & 364 & 20 \\
\hline $\begin{array}{l}\text { WHO COVID } \\
\text { Database }^{\text {b }}\end{array}$ & 54 & 51 & 1 & 0 & 0 & 0 & 0 \\
\hline $\begin{array}{l}\text { WHO Global } \\
\text { Health Library }\end{array}$ & 613 & 383 & 383 & 362 & 362 & 362 & 0 \\
\hline Total & 67,893 & 67,358 & 5392 & 4322 & 4320 & 1712 & 127 \\
\hline
\end{tabular}

${ }^{a}$ Retired or unavailable databases that were only part of the first-round search in June 2018

${ }^{\mathrm{b}} \mathrm{New}$ databases that were only part of the second-round search in October 2020

critical and/or promising supervision enhancementshighlighting key components, noteworthy results, and scaled or sustained approaches.

\section{Results}

Study selection

The first- and second-round database searches yielded a total of 67893 articles, of which 1727 met our primary criteria, including health sector relevance and publication in English in 2010 or later. The titles and abstracts of these publications were then reviewed further for relevance, yielding 127 articles. We then applied the CASP checklists and inclusion criteria of demonstrated positive results, yielding a total of 57 studies for the review (Fig. 2; Additional file 1).

\section{Analysis of HCW supervision enhancements}

We present the quantitative and qualitative findings of our review of successful HCW supervision interventions according to the conceptual framework areas: context, inputs, processes, and intervention results (Fig. 3). 


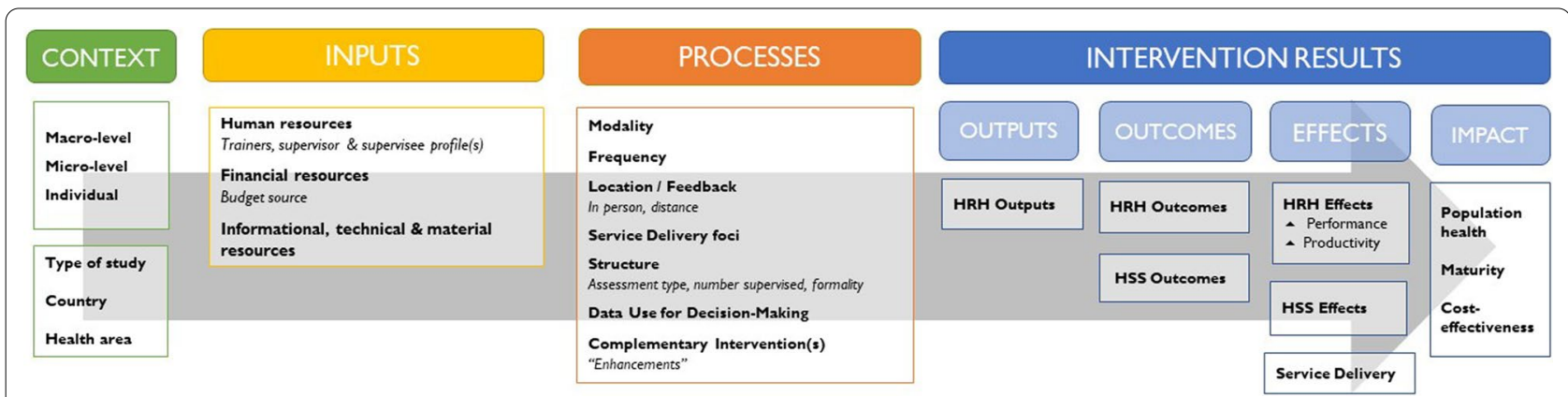

Fig. 1 Conceptual framework for reviewing enhanced supervision approaches (Source: HRH2030 2019. Adapted from GHWA [8], Dieleman et al. [7], and informed by Campbell et al. [3])

\section{Context}

Per our quantitative analysis, studies reviewed included 18 randomized controlled trials (32\%), 11 case studies (19\%), seven pre-post-tests (12\%), and six mixed methods (11\%). Forty-two of the studies documented approaches in Africa (74\%), 12 in Asia (21\%), and two in Latin America \& the Caribbean (4\%). Twenty studies focused on reproductive, maternal, newborn and child health (35\%), 14 on community health (25\%), ten on primary health care $(18 \%)$, eight in child health (14\%), four HIV/AIDS (7\%), and one on nutrition (2\%).

Per our qualitative analysis, the studies reviewed varied in focus and context. Many identified macro-level determinants of HCWs' baseline performance and related to the overall health system, socio-economic and political context, education system, and the labor market. Many supervision approaches in these studies were driven by a new national health sector policy, guideline, or training program, many of which focused on the professionalization or increased responsibility assigned to community health workers (CHWs). In addition, studies examined micro-level factors affecting HCW performance: workplace dynamics, individual attributes of health workers, high workloads, high turnover, absenteeism, inefficient processes, vast geographic distances, limited equipment and supplies, and limited community trust and health service utilization, especially for CHWs $[9,10]$.

\section{Inputs}

Supervision inputs we reviewed included human, financial, informational, material, and technical resources. For human inputs (e.g., supervisor and supervisee profiles), 14 studies observed supervision with district staff as the supervisors (25\%), nine with facility staff supervisors (16\%), and six with CHWs as supervisors (11\%); 28 were unspecified. Thirty studies (53\%) observed $\mathrm{CHWs}$ as the supervisees, with others focused on primary health care staff supervision, notably nurses. Forty-four supervisory interventions (77\%) were funded by non-governmental organizations (NGO) or donors; eight did not specify funding sources (14\%), three were cost-shared (5\%), one was funded by the facility (2\%), and one by the national budget (2\%). Of the 38 approaches, where supervisors used informational resources to prepare supervision, 14 approaches reviewed used training materials and 12 used facility-level records (21\%), while 12 others (21\%) were unspecified. For five approaches, mHealth applications supported $\mathrm{CHW}$-focused supervision with individual supervisee performance data or "crowdsourced" information from supervisees. Present in 40 approaches (70\%), the most frequently cited technical resource inputs were standards of care checklists, guidelines, or health worker job aids. Smartphones and mHealth applications were key inputs for the supervision approach in 13 (23\%) and $11(19 \%)$ of studies reviewed, respectively.

\section{Processes}

Supervision processes were analyzed in terms of inputs and processes by primary and secondary modality, frequency of supervision, location and delivery of feedback provided by the supervisor, structure of supervisor approach, as well as interventions complementary to supportive supervision-including enhancements for the supervisor, supervisee, and/or health system.

\section{Primary and secondary modalities}

We reviewed the primary and secondary modalities (i.e., methods or procedures) of the successful supervision approaches. Cited in 22 studies (39\%), quality improvement (QI) was the most common primary modality for supervision, often enhanced with various secondary modalities. Nineteen studies (33\%) documented a standard HR management approach, to supervision, though some of these interventions also employed a problem- or competency-based approach. Supervision interventions supporting task shifting/task sharing frequently used the 


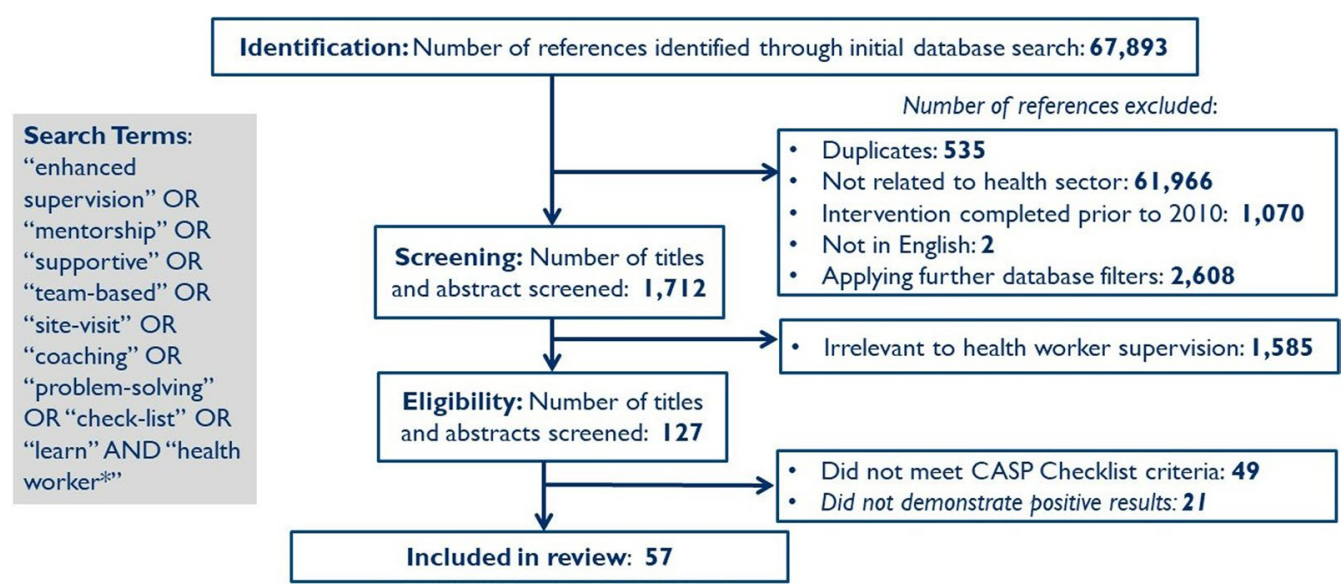

Fig. 2 Enhanced supervision review: database search results

QI modality, complemented by clinical mentoring. For example, applying monthly QI visits with clinical mentoring for nurses enhanced their scope and upgraded their skills for integrated management of adult and child illness and antenatal care services [11-13].
Of the 22 supervision approaches using QI as the primary modality, they contributed positive effects at all levels:

- Outputs: 21 approaches improved HRH skills, knowledge, and attitudes;

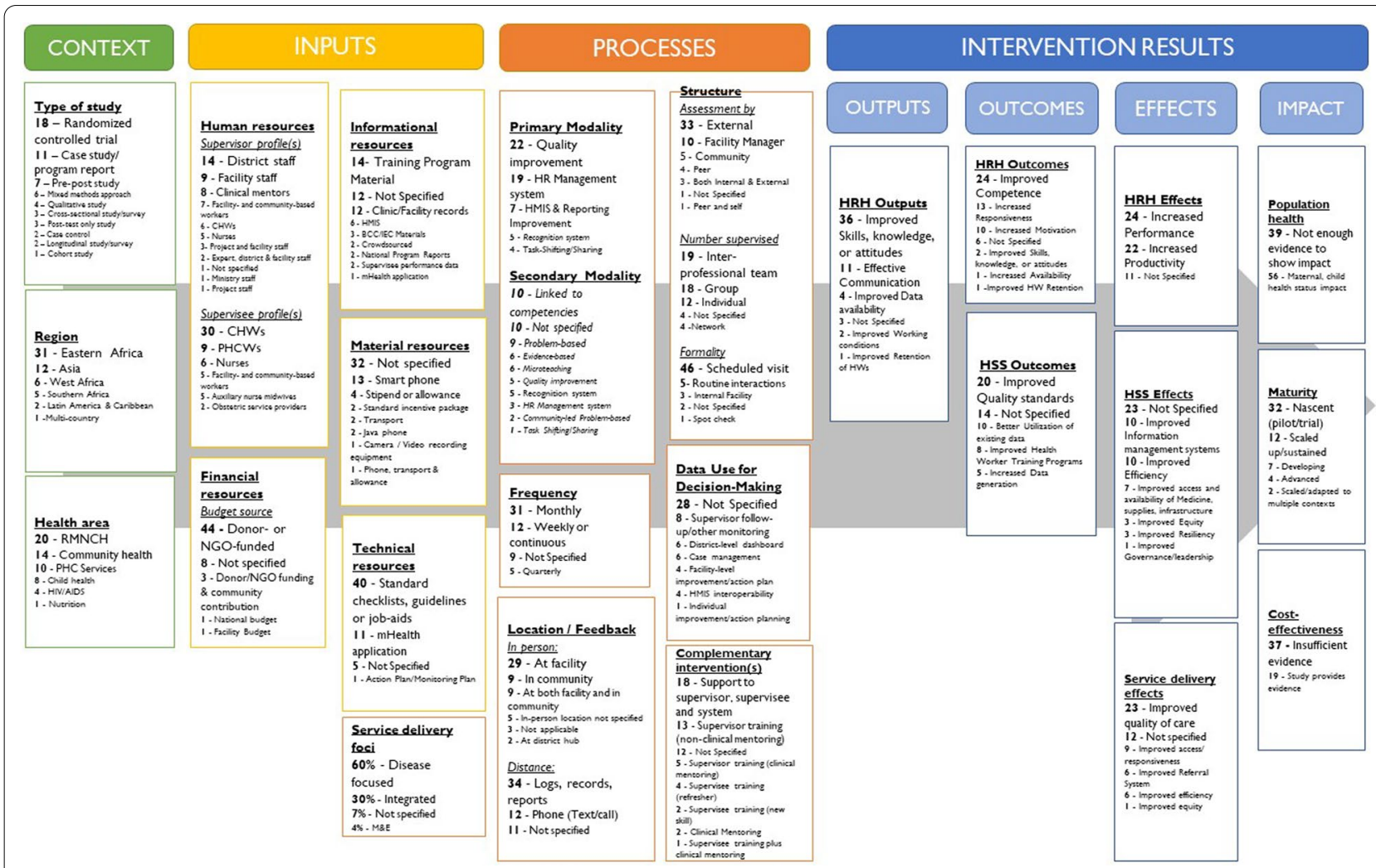

Fig. 3 Quantitative summary of enhanced supervision approaches reviewed using conceptual framework ( $n=57$ ) (Source: HRH2030, updated 2021. Adapted from GHWA [8], Dieleman et al. [7], and informed by Campbell et al. [3]) 
- Outcomes: 12 approaches improved HW competence, and seven approaches improved quality of standards of care;

- Effects: Six improved HRH performance and/or productivity and 12 improved the quality of care;

- Impact: Nine supported improved population health (compared to only three of the $19 \mathrm{HR}$ management systems approaches).

Our review supports the effectiveness of QI evidenced by previous reviews [14-16].

Using existing health management information system (HMIS) data (e.g., service delivery indicators) to inform the supervision approach supported a range of different health system goals, including task shifting of mid-level providers in Uganda [17]; improved CHW performance and system efficiencies for nutrition services in India [18]; improved quality of care for private sector and/or community-based health providers in malaria and family planning services across Africa and Asia [19]; and improved referral systems for CHWs [20, 21]. More research is needed to connect the impact of HMISinformed supervision approaches on service delivery effects. Four HMIS-focused supervision approaches demonstrated cost-effectiveness [22-25].

Combining supervisor training on clinical mentorship, plus supervisee clinical mentoring and supervision with a standardized job aid to support clinical decisionmaking helped $85 \%$ of ART patients initiate treatment with nurses in South Africa [26]. In Senegal, the combination of $\mathrm{HCW}$ performance support, mentoring, workplace improvements, and community support increased patients' informed choice by $86 \%$ over 6 months [27]. In Ghana, professionalizing district managers, supervisors, and communities to take a "client-centered" approach to HRH management provided staff with an effective enabling environment [28].

\section{Frequency}

In 46 of the 57 approaches (81\%), supervisory visits were scheduled. Of these 31 approaches scheduled monthly visits 12 scheduled weekly/continuous visits, and four scheduled quarterly visits. Twenty-three of the 31 approaches $(74 \%)$ with monthly supervision visits showed increased HCW productivity and performance, compared to only one of the four (25\%) that scheduled quarterly visits. More intensive, frequent, or continuous supervisory support was shown to be effective immediately after a new skill or task was imparted $[29,30]$. However, the quality of supervision was cited as more important than its frequency for $\mathrm{CHW}$ supervision in Uganda [31].

\section{Location and delivery of feedback}

We examined how and where supervision feedback was shared with HCWs. High-quality, timely feedback was shown to benefit both supervisors and supervisees whether provided in-person $(n=11)$, at a distance $(n=3)$, or in combination $(n=43)$. All in-person feedback for supervisory visits occurred at the health workers' place of work, in facilities or communities. For example, for CHWs supervised at a facility hub in Uganda, quarterly community-based supervision was combined with monthly on-site $\mathrm{CHW}$ meetings, contributing to their motivation and productivity [32]. In Ethiopia, Kenya, Malawi, Mozambique, and Tanzania, group CHW supervision at the facility combined with supervisor training served to improve motivation and the efficiency of supervisory processes [33, 34].

Of the 46 studies that assessed providing distance feedback, about 34 used existing records/reports, and 12 used phone/text messages. Distance feedback, including sharing summaries of service delivery data indicators, appeared to effectively complement in-person visits. Approaches with QI and HR management supervision modalities included feedback loops through sharing of reports, logs, and records. Whether texting or calling, phone communication was most frequently documented when the primary supervision modality was a recognition system [35, 36], and often documented more effective communication, increased health worker responsiveness, and increased data use [18, 37, 38]. Network-wide communications, such as WhatsApp group and peer-to-peer discussions supporting CHWs in Kenya, were considered favorable to reinforce standards of care and clinical guidance, provide activity updates, reinforce accountability through photo sharing, and recognize and motivate CHWs [36, 39].

\section{Structure of supervision approaches}

We reviewed the relationship of the supervisor to supervisee, the number of supervisees visited, and the level of formality of the visit (e.g., scheduled visit versus routine interaction). Of the 57 studies, 33 supervision approaches (58\%) used external evaluators to assess performance (e.g., individual or team who was not part of facility or community, often from a district, NGO, or project). Ten approaches relied on facility managers (18\%), five used community assessments (9\%), four used peer assessments (7\%) and one combined peer and self-assessments (2\%). Approaches combining internal and external assessments demonstrated effective support to interprofessional teams $[40,41]$. Thirty-six approaches used interprofessional or group assessments (63\%), of which many were to supervise CHWs. 


\section{Data-use for decision-making}

Twenty-eight (49\%) studies did not specify how supervisory visit data, reports and other information were used after the visit to inform subsequent actions and intervention. For QI modalities, continual data review may have been considered implicit by their authors but was not specified [12-14, 41-47].

\section{Complementary interventions}

We reviewed studies that used supervision plus other interventions to address underlying health system challenges that may hinder $\mathrm{HCW}$ performance. "Whole of system" approaches providing complementary support to HCW enabling environments, cited in 25 studies (44\%), were found to be effective across several areas, including improving health information systems, increasing process efficiencies, and providing better access to medicine, supplies, and health infrastructure. eighteen studies (32\%) focused on the quality of supervision by seeking to improve supervisors' HR management skills, some using the cascade model of clinical mentoring [12-14, 48]. Linking supervisee training to post-training supervision visits, whether for a new skill or a refresher training, was used in fewer instances. Task shifting-focused supervisory interventions generally followed $\mathrm{HCW}$ new skills training $[17,49]$.

\section{Intervention results}

We explored the interventions studied to establish a range of results across four separate but related levels: outputs, outcomes, effects, and impact, summarized in Fig. 3.

\section{Outputs}

Fifty-four supervision approaches demonstrated improvements in HRH outputs (95\%), of which 36 cited improved skills, knowledge, or attitudes. Some studies demonstrated results at several levels of Bloom's taxonomy of learning outcomes [50], from testing individual $\mathrm{HCW}$ knowledge and comprehension of health areas or tasks [11, 51-53] to measuring the application of specific clinical tasks and adherence to standards of care [11-13, $26,28,54]$. Improved attitudes documented by the studies included improved job satisfaction, commitment, and conscientiousness [33]; increased awareness of the importance of posting facility job aids [55]; increased recognition and support [31], and attitudes toward patients [45].

The second most frequent HRH output was effective communication, reporting, and information sharing. Eleven studies reported communication improvements (19\%), not only for HCWs and supervisors but also for
HCWs and clients and within facility teams. Outputs less frequently cited were improved data availability, improved working conditions, and improved retention of HCWs [37].

\section{Outcomes}

Most studies measured positive health workforce outcomes (e.g., improved availability, responsiveness, competence, or motivation) and HSS outcomes (e.g., improved quality standards, data use, service utilization, or workforce training programs). Twenty-four studies reported improved competence $(42 \%)$ and twenty studies reported improved quality standards (35\%). For CHW supervision studies, which focused primarily on RMNCH in India, Ethiopia, Kenya, Pakistan, and Tanzania, delegating supervisory roles to $\mathrm{CHW}$ supervisors or peers was shown to be effective, with results including improved CHW supervisee motivation [33, 35], safety [48], communication [39], and improved skills and standards of care [42].

When reviewing supervision modalities against outcomes, QI was the most frequently cited as improving health worker competence, with twenty studies, whereas HR management system modalities accounted reported improved motivation, cited in ten studies. Many studies discussed the importance of both constructive and positive feedback in improving HR management [52].

HSS outcomes related to data use-better utilization of existing data and increased data generation-were achieved through HMIS and reporting system modalities $[22,23,43,51,56]$, as well as through HR management system improvements [19, 20, 28, 57], QI [41, 43, 58], recognition systems $[35,36]$, and task-shifting/sharing modalities [17].

In three instances, where external, donor-supported project staff supervised providers alongside local government facility staff, the local government subsequently sustained the approaches $[23,24,55]$.

\section{Effects}

Most studies cited improvements at the effects level. Forty-six improved HRH performance and productivity (81\%), 45 improved service delivery (e.g., responsiveness, quality of care, and referral systems) (79\%), and 34 improved other health systems components (e.g., governance, financing, information, medicine, supplies, and infrastructure) (60\%). Specifically, 24 improved health worker performance, 22 increased productivity, and 23 improved quality of care. In terms of commonly reported health systems effects, ten approaches improved information management systems, ten improved efficiency, and seven improved access to and availability of supplies, medicine, and infrastructure. 


\section{Impact}

We explored the impact of supervision approaches in terms of population health, maturity, and cost-effectiveness. Eighteen studies (32\%) attributed impact on maternal, newborn, and child health $(\mathrm{MNCH})$ to supervision approaches [12, 13, 17, 21, 27, 36, 41, 42, 49, 52, 58-60]. Of these, four were reported to have been scaled up and sustained: the Safer Deliveries intervention in Zanzibar [20,21], a community-led supervision intervention with traditional birth attendants in Ecuador [41], a digital health intervention for integrated family health services in Bihar, India [38], and the MESH-QI approach for supervision and task sharing support for nurses providing antenatal care in Rwanda [11-13, 60].

Thirty-two approaches documented in this review (56\%) were at the nascent stage, or the lowest stage of maturity, and included pilots, trials, and other interventions not yet implemented at scale. Seven studies were at the developing stages (12\%), and four were at advanced stages $(7 \%)$.

Despite the successful results of all studies reviewed, only 12 studies (21\%) reported that the supervision enhancements were sustained or scaled beyond the study period. Two approaches-MESH-QI and the Health Network Quality Improvement System (HNQIS)—were scaled up and adapted to multiple contexts [11-13, 19, 60]. MESH-QI has been implemented in Rwanda, Liberia, and Malawi. HNQIS has been applied in 19 countries across different health areas and within both the public and private sectors. To better understand these two approaches, we conducted in-depth interviews with program implementers and developed two qualitative case studies that are structured according to our conceptual framework [61].

Five approaches-the MESH-QI, Safer Deliveries, and Bihar digital heath interventions, as well as a continuous quality improvement intervention for CHWs in South Africa and mentoring approach in Senegal-demonstrated population health impact, scalability, and costeffectiveness [11-13, 21, 38, 59, 60]. A CHW-focused digital health supervision approach for family planning in Tanzania also reported population-level impact and costeffectiveness; however, it was a nascent intervention [36].

\section{Discussion and recommendations}

The results from our review indicate that externally funded QI-based, digital, integrated $\mathrm{HCW}$ supervision enhancements demonstrate $\mathrm{HCW}$ performance and service delivery improvements across a range of health areas. However, there is very limited documentation of domestically funded, larger scale, longer term supervision enhancements that have been sustained over time with local investment. As many LMIC governments aim to institutionalize and sustain $\mathrm{CHW}$ programs, scalable, affordable supervision systems for community-based health workers become increasingly imperative.

A limitation of the study is that the indicated search criteria provided mainly peer-reviewed journals, and results were biased toward those studies with more substantial external funding. Additional documentation and research, including cost-effectiveness studies, should be conducted as nascent approaches are brought to scale, to enable thorough analysis of the modalities that can sustainably impact population health.

While beyond the scope of the review, we are aware that some approaches have been sustained and/or scaled. For example, MESH-QI remains a technical approach with comprehensive guidance that Partners in Health and country governments continue to implement [62]. Safer Deliveries supervision approaches have been implemented and scaled across Zanzibar, Tanzania, with continued collaboration between D-tree International and the Zanzibar Ministry of Health [63].

Stewardship for implementing, evaluating, and financing effective HCW supervision approaches must further shift from external partners to national and subnational governments. To address the dearth of country-led peerreviewed literature on $\mathrm{HCW}$ supervision, ministries of health should engage with local research partners, schools of public health, and national health institutes to strengthen their operational research capacity to evaluate supervision approaches.

To implement effective HCW supervision, we recommend national and subnational stakeholders seek to contextualize, integrate, and optimize the following supervision enhancements within health systems:

Evidence-based, QI tools and processes. QI methods streamlining $\mathrm{HCW}$ performance management data with other health system performance data and information flows can help HCW supervisors to effectively assess quality gaps, address underlying factors, and continuously monitor and adapt through collaborative problemsolving, measurement, and data use. Clinical mentoring can effectively complement routine supervision, particularly for task shifting/task sharing. Constructive feedback should be timely and include positive recognition to motivate health workers.

Digital supervision data and supervision processes. Using digital checklists or job aids with algorithms can facilitate adherence to standards and deliver the most appropriate and immediate feedback. This is critical for supervising health workers who serve in remote locations and/or those working in emergency contexts, such as a pandemic, civil strife, or natural disaster. In health systems with reliable access to basic hardware and software, electricity, and connectivity, collecting and disseminating 
supervision data digitally can support potential advantages and efficiencies for the supervisor, including reducing paper-based data management tasks and automating analysis to demonstrate performance trends or target supervisee support needs. Digital data-including patient-level data-generated by remote or communitybased HCWs, helps supervisors follow supervisees' activities, monitor quality, and improve feedback loops [36].

Improved interoperability and use of national HMIS. Reviewing facility and service area performance and prioritizing supervisory support to the lowest performing areas can help target resource allocation and improve quality and equity. Integrating supervision systems' information into the same platforms that host other health systems data (e.g., DHIS2), may offer more opportunities to provide real-time information and feedback to the supervisor and supervisee to promote evidence-based problem solving. Integrating supervision data with an HMIS could promote efficiencies and possibly cost-effectiveness for $\mathrm{HCW}$ performance and health system management processes. Integrating or linking health worker performance data to health systems outputs, including the quantity and quality of specific services in comparison with data on the population of district-level dashboards [19], can be especially useful when ensuring the effectiveness of community-tofacility referral systems [21].

To sustain effective supervision, we recommend to:

Scale and replicate successful models across service delivery areas and geographies. Promising supervision systems can be adapted to expand use for the public and private sector, and for facility- and communitybased workers. Supervision approaches should not create a vertical system competing with other national or district level activities, but rather demonstrate adaptability to multiple programs, and facilitate targeted supervision within an integrated context in response to an assessment of facility-wide performance.

Expand and institutionalize supervision to reach, prepare, protect, and support frontline health workers. The COVID-19 pandemic has placed additional physical, biological, psychosocial and occupational risks on health workers and compounds the challenges they face to deliver high-quality care, especially as they adapt and respond to an emerging threat [64]. Traditional methods of routine supervision have been interrupted or curtailed due to new facility regulations, physical distancing requirements, and reduced mobility and time for supervisors and program managers to dedicate to mentoring and training, including to apply new COVID-19 and infection prevention and control protocols. Institutionalizing supervision is important to prepare for emergencies and establish support mechanisms for frontline health worker. Supervision enhancements-including using digital platforms, communicating by phone/text, conducting remote training, and using digital checklists - can be meaningful if in-person visits are not possible to fill the gaps, when HCWs need more support than ever.

Transition and sustain efforts with local human and financial resources. Community engagement and feedback on the quality of services can complement district- or manager-level supervisory efforts, especially for supervising community health workers as they are increasingly professionalized [65]. Delegating supervisory roles to both facility- and community-based workers can increase the number of supervisory contacts and improve accountability, especially when introducing or scaling a new CHW task or when facility-based supervisors face high workloads. A whole of system approach may help to address the HCW enabling environment more locally and sustainably. Supervision approaches should engage a range of stakeholders across local systems, including district managers, peers, and communities. For those who least benefit from routine supervision, such as CHWs, programs can utilize interprofessional or group assessments. These approaches can promote efficiencies, where site or field visits consume supervisor time and resources are not possible due to travel restrictions.

\section{Conclusion}

Effective supervision enhancements and innovations should be better integrated, scaled, and sustained within existing systems to improve access to quality health care. Enhanced health worker supervision can better increase $\mathrm{HCW}$ performance and strengthen health systems when it is informed by and promotes continual, routine use of supervisory and health system information using a QI-focused modality. Sharing health worker supervision data through digital platforms to deliver immediate feedback loops for the supervisees, health systems actors, and local communities promotes greater awareness of performance issues to foster better awareness, accountability, and action.

Sustaining successful supervision approaches requires adequate human and financial resources, integrating visits into other health system activities, and adapting beyond a single health worker type or disease area. Enhancements are too often one-off, donorfunded approaches that are program-driven rather than country-led, whole-system changes that can be scaled up and sustained over time. Further countryled research is recommended to assess the outputs, 
outcomes, effects, and impact of the same enhanced supervision approach across different country contexts and health areas, for different types of health workers (e.g., public and private sector, facility- and community-based), and at different stages of maturity.

\section{Abbreviations}

CASP: Critical Appraisal Skills Program; CHW: Community health worker; $\mathrm{HRH}$ Human resources for health; HCW: Health care worker; HRH2030: Human Resources for Health in 2030 Program; LMIC: Low- and middle-income country; NGO: Non-governmental organization; QI: Quality improvement; USAID: United States Agency for International Development.

\section{Supplementary Information}

The online version contains supplementary material available at https://doi. org/10.1186/s12960-021-00692-y.

Additional file 1. Supervision review inventory and taxonomy lists.

\section{Acknowledgements}

We gratefully acknowledge Julie Becker, Wanda Jaskiewicz, and Elizabeth Walsh, Chemonics International and Emma Dominguez, formerly Chemonics International, for their comments and support to the draft manuscript. RM acknowledges Katherine Farnsworth, USAID Office of Health Systems, for her technical insights. RD also acknowledges Niina Taapopi for her logistical support.

\section{Disclaimer}

The views and opinions expressed in this paper are those of the authors and not necessarily the views and opinions of the United States Agency for International Development.

\section{Authors' contributions}

$\mathrm{RD}$ designed the study, participated in the selection of articles and analysis of data, and drafted the manuscript. DM designed the study, participated in the selection of articles and analysis of data, and contributed to draft versions of the manuscript. MB and SA participated in the selection of articles and analysis of data, and substantially contributed to draft versions of the manuscript. RM advised on the study design and substantially contributed to draft versions of the manuscript. All authors read and approved the final manuscript.

\section{Funding}

Financial support for this systematic review from the United States Agency for International Development under the Cooperative Agreement No. AID-OAA-A-15-00046.

\section{Availability of data and materials}

The data sets generated or analyzed during this study are included within this article and its Additional file.

\section{Declarations}

\section{Ethics approval and consent to participate}

Not applicable.

\section{Consent for publication}

Not applicable.

\section{Competing interests}

The authors declare that they have no competing interests.

\section{Author details}

${ }^{1} \mathrm{HRH} 2030$ Program, Chemonics International, 1717 H Street NW, Washington, DC 20006, United States of America. ${ }^{2}$ Human Resources for Health Consultant,
Formerly With Chemonics International, PO Box 26432-00100, Nairobi, Kenya. ${ }^{3}$ Office of Health Systems, Bureau for Global Health, United States Agency for International Development, 1300 Pennsylvania Avenue NW, Washington, DC 20004, United States of America.

Received: 8 June 2021 Accepted: 12 November 2021

Published online: 06 January 2022

\section{References}

1. UHC 2030 International Health Partnership. Healthy systems for universal health coverage-a joint vision for healthy lives. 2017. https://www. uhc2030.org/fileadmin/uploads/uhc2030/Documents/About_UHC2030/ mgt_arrangemts_docs/UHC2030_Official_documents/UHC2030_vision_ paper_WEB2.pdf. Accessed 28 May 2021.

2. World Health Organization. Declaration of Astana. Global conference on primary health care. Astana, Kazakhstan, 25-26 October, 2018. WHO/HIS/ SDS/2018.61.

3. Campbell J, Dussault G, Buchan J, Pozo-Martin F, Guerra Arias M, Leone C, Siyam A, Cometto G. A universal truth: no health without a workforce. Forum report third global forum on human resources for health. Global Health Workforce Alliance and World Health Organization; 2013. ISBN 978-92-4-150676-2. https://www.who.int/workforcealliance/knowledge/ resources/GHWA-a_universal_truth_report.pdf?ua=1. Accessed 28 May 2021.

4. Kruk ME, Gage AD, Arsensault C, Jordan K, Leslie HH, Roder-DeWan S, et al. High-quality health systems in the sustainable development goals era: time for a revolution. Lancet Glob Health. 2018. https://doi.org/10. 1016/S2214-109X(18)30386-3.

5. Rowe A, Rowe SY, Peters DH, Holloway KA, Chalker J, Ross-Degnan D, et al Effectiveness of strategies to improve health-care provider practices in low income and middle-income countries: a systematic review. Lancet Glob Health. 2018. https://doi.org/10.1016/S2214-109X(18)30398-X.

6. Bailey C, Blake C, Schriver M, Cubaka VK, Thomas T, Hilber AM. A systematic review of supportive supervision to improve primary health care services in Sub-Saharan Africa. Int J Gynaecol Obstet. 2016;132(1):117-25. https://doi.org/10.1016/j.ijgo.2015.10.004.

7. Dieleman M, Gerretsen B, van der Wilt GJ. Human resource management interventions to improve health workers' performance in low and middle income countries: a realist review. Health Res Policy Syst. 2009. https:// doi.org/10.1186/1478-4505-7-7.

8. Global Health Workforce Alliance (GHWA). Improving health worker productivity and performance in the context of universal health coverage: the roles of standards, quality improvement, and regulation. 2014. https://www.who.int/workforcealliance/media/news/2014/WG7_Produ ctivityandperformance.pdf. Accessed 28 May 2021.

9. Jaskiewicz W, Tulenko K. Increasing community health worker productivity and effectiveness: a review of the influence of the work environment. Hum Resour Health. 2012. https://doi.org/10.1186/1478-4491-10-38.

10. Kalua K, Gichango M, Barassa E, Eliah E, Lewallen S, Courtright P. A randomised controlled trial to investigate effects of enhanced supervision on primary eye care services at health centres in Kenya, Malawi and Tanzania. BMC Health Serv Res. 2014;14(Suppl 1):S6. https://doi.org/10. 1186/1472-6963-14-S1-S6.

11. Anatole $M$, Magge $H$, Redditt V. Nurse mentorship to improve the quality of health care delivery in rural Rwanda. Nurs Outlook. 2012. https://doi. org/10.1016/j.outlook.2012.10.003.

12. Manzi A, Magge H, Hedt-Gauthier BL, Michalis AP, Cyamatere FR, Nyirazinyoye L, Hirschorn LR, Ntaganira J. Clinical mentorship to improve pediatric quality of care at the health centers in rural Rwanda : a qualitative study of perceptions and acceptability of health care workers. BMJ Health Serv Res. 2014. https://doi.org/10.1186/1472-6963-14-275.

13. Manzi A, Nyirazinyoye L, Ntganira J, Magge H, Bigirimana E, Mukanzabikeshimana $L$, et al. Beyond coverage: improving the quality of antenatal care delivery through integrated mentorship and quality improvement at health centers in rural Rwanda. BMC Health Serv Res. 2018. https://doi. org/10.1186/s12913-018-2939-7.

14. Tawfik Y, Segall M, Necochea E, Jacob T. Finding common ground: harmonizing the application of different quality improvement models in maternal, newborn, and child health programs. 2010. https://www. 
healthynewbornnetwork.org/hnn-content/uploads/Finding_common_ ground_Oct10.pdf. Accessed 28 May 2021.

15. Ovretveit J, Broughton E. Towards more effective spread of improvement methods in lower and middle income countries: a synthesis of the research. Bethesda: University Research Company, LLC. https://www. semanticscholar.org/paper/Towards-more-effective-spread-of-impro vement-in-and/2b2587b41349fb7d5716b2ba848a7deebd68b8c4. Accessed 28 May 2021.

16. Hill Z, Dumbugh M, Benton L, Källander K, Strachan D, ten Asbroek A, et al. Supervising community health workers in low-income countries a review of impact and implementation issues. Glob Health Action. 2014. https://doi.org/10.3402/gha.v7.24085.

17. Naikoba S, Senjovu KD, Mugabe P, McCarthy CF, Riley PL, Kadengye DT, Dalal S. Improved HIV and TB knowledge and competence among midlevel providers in a cluster-randomized trial of one-on-one mentorship for task shifting. J Acquir Immune Defic Syndr. 2017. https://doi.org/10. 1097/QAl.0000000000001378.75(5).

18. Kaphle S, Matheke-Fischer M, Lesh N. Effect of performance feedback on community health workers' motivation and performance in Madhya Pradesh, India: a randomized controlled trial. JMIR Public Health Surveill. 2016. https://doi.org/10.2196/publichealth.3381.

19. Lussiana C, Dale M, Sato L, Patry J, Makoyo J, Macaringue L, Thein ST, Nuñez L. Addressing quality improvement of health service provision in DHIS2: how technology advancements are driving adaptive monitoring measures. population services international. DHIS2 Academy Presentation. 2016.

20. Deussom RH, Mitchell M, Ruben JD. Using mobile technology to address the "three delays" to reduce maternal mortality in Zanzibar. Int J UserDriven Healthc. 2014. https://doi.org/10.4018/ijudh.2014010103.

21. Battle JD, Farrow L, Tibajuka J, Mitchell M. mHealth for safer deliveries: a mixed methods evaluation of the effect of an integrated mobile health intervention on maternal care utilization. Healthcare. 2015. https://doi. org/10.1016/j.hjdsi.2015.10.011.

22. Campbell N, Schiffer E, Buxbaum A, McLean E, Perry C, Sullivan TM. Taking knowledge for health the extra mile: participatory evaluation of a mobile phone intervention for community health workers in Malawi. Glob Health Sci Pract. 2014. https://doi.org/10.9745/GHSP-D-13-00141.

23. Biemba G, Chiluba B, Yeboah-Antwi K, Silavwe V, Lunze K, Mwale RM, et al. A mobile-based community health management information system for community health workers and their supervisors in 2 districts of Zambia. Glob Health Sci Pract. 2017. https://doi.org/10.9745/GHSP-D-16-00275.

24. Nepal P, Schwarz R, Citrin D, Thapa A, Acharya B, Acharya Y, et al. Costing analysis of a pilot community health worker program in rural Nepal. Glob Health Sci Pract. 2020. https://doi.org/10.9745/ghsp-d-19-00393.

25. Davis A, Nascimento ND, Chapman J, Donco R, Velthuaz D. A qualitative comparative analysis of the drivers of HIV status knowledge in orphans and vulnerable children in Mozambique. Glob Health Sci Pract. 2020. https://doi.org/10.9745/ghsp-d-20-00311.

26. Green A, de Azevdo V, Patten G, Davies M-A, Ibeto M, Cox V. Clinical mentorship of nurse initiated antiretroviral therapy in Khayelitsha, South Africa: a quality of care assessment'. PLoS ONE. 2014. https://doi.org/10. 1371/journal.pone.0098389.

27. Gueye B, Wesson J, Koumtingue D, Stratton S, Viadro C, Talla H, Dioh E, et al. Mentoring, task sharing, and community outreach through the TutoratPlus approach: increasing use of long-acting reversible contraceptives in Senegal. Glob Health Sci Pract. 2016. https://doi.org/10.9745/ GHSP-D-15-00328.

28. Aikins M, Laar A, Nonvignon J, Sackey S, Ikeda T, Woode G, et al. Evaluation of facilitative supervision visits in primary health care service delivery in Northern Ghana. BMC Health Serv Res. 2013. https://doi.org/10.1186/ 1472-6963-13-358.

29. Som M, Panda B, Pati S, Nallala S, Anasuya A, Chauhan AS, et al. Effect of supportive supervision on routine immunization service delivery—a randomized post-test study in Odisha. Glob Health Sci Pract. 2014. https:// doi.org/10.5539/gjhs.v6n6p61.

30. Panda B, Pati S, Nallala S, Chauhan AS, Som M, Zodpey S. How supportive supervision influences immunization session site practices: a quasiexperimental study in Odisha, India. Glob Health Action. 2015. https://doi. org/10.3402/gha.v8.25772.

31. LudwickT, Turyakira E, Kyomuhangi T, Manalil K, Robinson S, Brenner JL. Supportive supervision and constructive relationships with healthcare workers support CHW performance: use of a qualitative framework to evaluate CHW programming in Uganda. Hum Resour Health. 2018. https://doi.org/10.1186/s12960-018-0272-1.

32. Brunie A, Wamala-Mucheri P, Otterness $C$, Akol A, Chen M, Bufumbo L, Weaver M. Keeping community health workers in Uganda motivated: key challenges, facilitators, and preferred program inputs. Glob Health Sci Pract. 2014. https://doi.org/10.9745/ghsp-d-13-00140.

33. Kok MC, Vallières F, Tulloch $\mathrm{O}$, Kumar MB, Kea AZ, Karuga R, et al. Does supportive supervision enhance community health worker motivation? A mixed-methods study in four African countries. Health Policy Plan. 2018. https://doi.org/10.1093/HEAPOL/CZY082.

34. Mkumbo E, Hanson C, Penfold S, Manzi F, Schellenberg J. Innovation in supervision and support of community health workers for better newborn survival in southern Tanzania. Int Health. 2014. https://doi.org/ 10.1093/inthealth/ihu016.

35. Henry JV, Winters N, Lakati A, Oliver M, Geniets A, Mbae SM. Enhancing the supervision of community health workers with WhatsApp mobile messaging: qualitative findings from 2 low-resource settings in Kenya. Glob Health Sci Pract. 2016. https://doi.org/10.9745/GHSP-D-15-00386.

36. Agarwal S, Lasway C, L’Engle K, Homan R, Layer E, Ollis S, Braun R, et al. Amily planning counseling in your pocket: a mobile job aid for community health workers in Tanzania. Glob Health Sci Pract. 2016. https://doi. org/10.9745/GHSP-D-15-00393.

37. Mcauliffe E, Daly M, Kamwendo F, Masanja H, Sidat M, de Pinho H. The critical role of supervision in retaining staff in obstetric services: a three country study. PLOS ONE. 2013. https://doi.org/10.1371/journal.pone. 0058415.

38. Grant C, Nawal D, Guntur SM, Kumar M, Chauduri I, Galavotti C, et al. "We pledge to improve the health of our entire community": improving health worker motivation and performance in Bihar, India through teamwork, recognition, and non-financial incentives. PLoS ONE. 2018. https:// doi.org/10.1371/journal.pone.0203265.

39. Rabbani F, Shipton L, Aftab W, Sangrasi K, Perveen S, Zahidie A. Inspiring health worker motivation with supportive supervision: a survey of lady health supervisor motivating factors in rural Pakistan. BMC Health Serv Res. 2016. https://doi.org/10.1186/s12913-016-1641-x.

40. Okuga M, Kemigisa M, Namatamba S, Namazzi G, Waiswa P. Engaging community health workers in maternal and newborn care in eastern Uganda. Glob Health Action. 2015. https://doi.org/10.3402/gha.v8.23968.

41. Broughton E, Hermida J, Hill K, Sloan N, Chavez M, Gonzalez D, et al. Evaluation of an intervention to improve essential obstetric and newborn care access and quality in Cotopaxi, Ecuador. Front Public Health. 2016. https://doi.org/10.3389/fpubh.2016.00247.

42. Gupta M, Tripathy JP, Jamir L, Sarwa A, Sinha S, Bhag C. Improving quality of home-based postnatal care by microteaching of multipurpose workers in rural and urban slum areas of Chandigarh, India: a pilot study. Adv Med Educ Pract. 2016. https://doi.org/10.2147/AMEP.S111697.

43. Marshall A, Fehringer J. Supportive supervision in monitoring and evaluation with community-based health staff in HIV programs - a case study from Ethiopia. Measure Evaluation. 2014. https://www.measureeva luation.org/resources/publications/sr-14-98/at_download/document Accessed 28 May 2021.

44. Frimpong JA, Helleringer S, Awoonor-Williams JK, Yeji F, Phillips JF. Does supervision improve health worker productivity? Evidence from the Upper East Region of Ghana. Trop Med Int Health. 2011. https://doi.org/ 10.1111/j.1365-3156.2011.02824.x.

45. Bello DA, Hassan ZI, Afolaranmi TO, Tagurum YO, Chirdan OO, Zoakah AI. Supportive supervision: an effective intervention in achieving high quality malaria case management at primary health care level in Jos, Nigeria. Ann Afr Med. 2013. https://doi.org/10.4103/1596-3519.122695.

46. Magge H, Anatole M, Cyamatare FR, Mezzacappa C, Nkikabahizi F, Niyonzima $S$, et al. Mentoring and quality improvement strengthen integrated management of childhood illness implementation in rural Rwanda. Arch Dis Child. 2015. https://doi.org/10.1136/archdischild-2013-305863.

47. Daniels K, Nor B, Jackson D, Ekström E-C, Doherty T. Supervision of community peer counsellors for infant feeding in South Africa: an exploratory qualitative study. Hum Resour Health. 2010. https://doi.org/10.1186/ 1478-4491-8-6.

48. Ajeani J, Ayiasi RM, Tetui M, Ekirapa-Kiracho E, Namazzi G, Kananura RM, et al. A cascade model of mentorship for frontline health workers in rural health facilities in Eastern Uganda: processes, achievements and lessons. 
Glob Health Action. 2017. https://doi.org/10.1080/16549716.2017.13454 97.

49. MCHIP. Promising practices in maternal and newborn health and family planning and reproductive health in Ethiopia in 2012. https://www. mchip.net/wp-content/uploads/2017/12/Ethiopia.pdf. Accessed 28 May 2021.

50. Bloom BS, Englehart EJ, Hill WH, Krathwohl D. Taxonomy of educational objectives, handbook I: the cognitive domain. New York: David McKay Co Inc:; 1965.

51. Zakus D, Moussa M, Ezechiel M, Yimbesalu JP, Orkar P, et al. Clinical evaluation of the use of an mhealth intervention on quality of care provided by community health workers in southwest Niger. J Glob Health. 2019. https://doi.org/10.7189/jogh.09.010812.

52. Kambarami RA, Mbuya MN, Pelletier D, Fundira D, Tavengwa NV, Stoltzfus RJ. Factors associated with community health worker performance differ by task in a multi-tasked setting in rural Zimbabwe. Glob Health Sci Pract. 2016. https://doi.org/10.9745/GHSP-D-16-00003.

53. Aftab W, Rabbani F, Sangrasi K, Perveen S, Zahidie A, Qazi SA. Improving community health worker performance through supportive supervision: a randomised controlled implementation trial in Pakistan. Acta Paediatr. 2018. https://doi.org/10.1111/apa.14282.

54. Barnhart DA, Speigelman D, Zigler CM, Kara N, Delaney MM, Kalita T, et al. Coaching intensity, adherence to essential birth practices, and health outcomes in the BetterBirth trial in Uttar Pradesh, India. Glob Health Sci Pract. 2020. https://doi.org/10.9745/GHSP-D-19-00317.

55. Tadesse T, Abebe F, Hawkins A, Pearson J. Improving infection prevention and control in Ethiopia through supportive supervision of health facilities. Arlington, VA: AIDSTAR-One. https://aidsfree.usaid.gov/sites/default/files/ aidstar-one_ipc_ethiopia_supportive_supervision_report.pdf. Accessed 28 May 2021

56. He P, Yuan Z, Liu Y, Li G, Lv H, Yu J, Harris MF. An evaluation of a tailored intervention on village doctors use of electronic health records. BMC Health Serv Res. 2014. https://doi.org/10.1186/1472-6963-14-217.

57. MEASURE scaling mHealth for community-based health information systems lessons and best practices acknowledgments. 2017. https://www. measureevaluation.org/resources/publications/gr-17-004. Accessed 28 May 2021.

58. Borkum E, Sivasankaran A, Sridharan S, Rotz D, Sethi S, Manoranjini M, et al. Evaluation of the information and communication technology (ICT) continuum of care services (CCS) intervention in Bihar. Princeton: Mathematica Policy Research. 2015. https://www.mathematica.org/ourpublications-and-findings/publications/evaluation-of-the-informationand-communication-technology-ict-continuum-of-care-services-ccs. Accessed 28 May 2021.

59. George G, Mudzingwa T, Horwood C. The cost of the training and supervision of community health workers to improve exclusive breastfeeding amongst mothers in a cluster randomised controlled trial in South Africa. BMC Health Serv Res. 2020. https://doi.org/10.1186/s12913-020-4913-4.

60. Manzi A, Mugunga JC, lyer HS, Magge H, Nkikiabahizi F, Hirschorn LR. Economic evaluation of a mentorship and enhanced supervision program to improve quality of integrated management of childhood illness care in rural Rwanda. PLoS ONE. 2018. https://doi.org/10.1371/journal.pone. 0194187.

61. Human Resources for Health in 2030 Program (HRH2030). Enhanced supervision approaches: phase 1 landscape analysis findings report. Washington, DC: Chemonics International. 2019. https://hrh2030pro gram.org/wp-content/uploads/2019/06/HRH2030. Accessed 28 May 2021.

62. Manzi A, Kirk C. Hirschhorn LR. Mentorship and enhanced supervision for healthcare and quality improvement (MESH-QI) implementation guide. Partners In Heath 2017. https://www.pih.org/sites/default/files/2017-12/ MESH\%20Q1\%20Final\%20web\%2012.2017.pdf. Accessed 05 Oct 2021.

63. Fulcher IR, Nelson AR, Tibaijuka Jl, Seif SS, Lilienfeld S, Abdalla OA, et al. Improving health facility delivery rates in Zanzibar, Tanzania through a large-scale digital community health volunteer programme: a process evaluation. Health Policy Plan. 2020. https://doi.org/10.1093/heapol/ czaa068.

64. Concha-Barrientos M, Imel ND, Driscoll T, Steenland NK, Punnett L, Fingerhut MA, et al. Selected occupational risk factors. In: Ezzati M, Lopez AD, Rodgers A, Murray CJL, editors. Comparative quantification of health risks.
Geneva: World Health Organization; 2004. https://www.who.int/healt hinfo/global_burden_disease/cra/en/. Accessed 28 May 2021.

65. World Health Organization. WHO guideline on health policy and system support to optimize community health worker programmes. Geneva: World Health Organization; 2018. Licence: CC BY-NC-SA 3.0 IGO. https:// apps.who.int/iris/bitstream/handle/10665/275474/9789241550369-eng. pdf?ua=1. Accessed 28 May 2021.

\section{Publisher's Note}

Springer Nature remains neutral with regard to jurisdictional claims in published maps and institutional affiliations.
Ready to submit your research? Choose BMC and benefit from:

- fast, convenient online submission

- thorough peer review by experienced researchers in your field

- rapid publication on acceptance

- support for research data, including large and complex data types

- gold Open Access which fosters wider collaboration and increased citations

- maximum visibility for your research: over $100 \mathrm{M}$ website views per year

At BMC, research is always in progress.

Learn more biomedcentral.com/submissions 